\title{
SHEETFLOW SEDIMENT TRANSPORT UNDER SKEWED - ASYMMETRIC WAVES AND CURRENTS
}

\author{
Le Phuong Dong ${ }^{1}$ and Shinji Sato ${ }^{1}$
}

\begin{abstract}
Prototype scale laboratory experiments have been conducted to investigate the sheetflow sediment transport of uniform sands under different skewed-asymmetric oscillatory flows. Experimental results reveal that in most of the case with fine sand, the "cancelling effect", which balances the on-/off-shore net transport under pure asymmetric/skewed flows and results a moderate net transport, was developed for combined skewed-asymmetric flow. However, under some certain conditions $(\mathrm{T}>5 \mathrm{~s})$ with coarse sands, the onshore sediment transport was enhanced by $50 \%$ under combined skewed-asymmetric flows. Sand transport mechanism under oscillatory sheetflow conditions is also studied by comparing the maximum bed shear stress and the phase lag parameter at each half cycle. A comparison of measurements including the new experimental data with a number of practical sand transport formulations shows that the Dong et al. (2013) formulation performs the best in predicting the measured net transport rates over a wide range of experimental conditions.
\end{abstract}

Keywords: sheetflow sand transport; skewed-asymmetric flows; net transport rates modeling

\section{INTRODUCTION}

When waves approach the coast and propagate into the shallower water depth, the waveform alters from the sinusoidal shape in the deep water to a more asymmetric form with a peaky and sharp crest separated by a longer and shallower trough (skewed-waves). Once waves break and enter the surf zone, they could attain a pitched-forward shape with a steep front face and a mild rear face (asymmetric waves). The mechanism for the wave shape transformation is mainly caused by the nonlinear, near triad resonant wave interactions, which amplify the higher harmonics (Doering and Bowen, 1995; Ruessink et al., 2009; Sato et al., 1992). With the changes of wave shape with water depth, the corresponding orbital velocity near the bed also shows a similar variation. Under the pure-skewed waves, the near bottom orbital velocity varies between the crest and trough periods, whereas the acceleration remains approximately symmetric between the two half cycles (Fig 1a). As waves continue to shoal, they transform to a skewed-asymmetric shape with both near bottom velocity and acceleration varies between onshore and offshore directions (Fig 1b). Closer to the shore, waves are formed like saw tooth shape with the near bottom orbital velocity becomes symmetric while flow acceleration becomes asymmetric between two half wave cycles (Fig 1c).
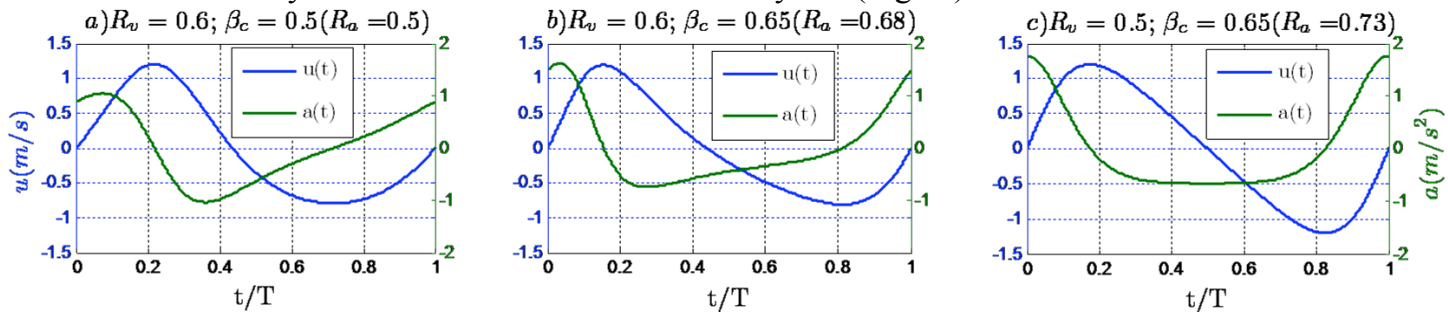

Figure 1. Velocity and acceleration profile of: a) pure velocity-asymmetric (or skewed) flow; b) Mixed skewedasymmetric flow; c) pure acceleration-asymmetric (or asymmetric) flow

The existence of different wave shapes may lead to the different sediment transport behaviors. For instance, experiments under skewed oscillatory flows found that if the response time of sediment is comparable to the wave period, the sand particles entrained during the positive half cycles are transported to the opposite direction by the successive negative velocity. Especially, for highly asymmetric oscillation or under high flow regime, this effect sometimes is large enough to invert the sand to opposite direction with the maximum velocity (Ahmed and Sato, 2003; Dibajnia and Watanabe, 1992; Lwin et al., 2011; O'Donoghue and Wright, 2004a; O'Donoghue and Wright, 2004b; Ribberink and Al-Salem, 1994; Ribberink and Chen, 1993). In contrast, under asymmetric flows (symmetric velocity but asymmetric/skewed acceleration profile), sand is always transported to onshore direction due to higher bed shear stress and longer settling time for sand depositing back to bottom during the onshore phase (Mina and Sato, 2004; Van der A et al., 2010a; Watanabe and Sato, 2004). However, up to now, only a few experiments (4 tests) were conducted with the combined skewed-asymmetric flows (e.g., those in Ruessink et al., 2011; Silva et al., 2011). Therefore, sand transport tendency for the

\footnotetext{
${ }^{1}$ Department of Civil engineering, The University of Tokyo, 7-3-1 Hongo, Bunkyo ku, Tokyo 113-8656, Japan
} 
mixed skewed-asymmetric oscillations is still unclear due to the lack of sufficient experimental data. This study aims to investigate the effect of different wave shapes on net sand transport rates under the oscillatory sheetflow conditions. It was motivated by the fact that most natural waves in surf zone produce mixed skewed-asymmetric oscillatory flows (Ruessink et al., 2009). The mechanism of sand transport under oscillatory sheetflow conditions is studied by comparing the maximum bed shear stress and the phase lag parameter at each half cycle. At the end, net transport rates measured in this study together with comprehensive laboratory data available to date were collected and compared with some existing sand transport models.

\section{EXPERIMENTS}

\section{Experimental conditions}

A set of experimental data has been obtained using the Oscillatory Flow Tunnel (OFT) at the University of Tokyo. Skewed-asymmetric oscillations have been generated based on the analytical approximation wave form (Abreu et al., 2010):

$$
u_{\infty}(t)=u_{w} f \frac{\left[\sin (\omega t)+\frac{r \sin \Phi}{1+\sqrt{1-r^{2}}}\right]}{1-r \cos (\omega t+\Phi)}
$$

where $u_{w}$ is the velocity amplitude (Fig.2), $\omega=2 \pi / T$ with $T$ being the flow period; $\Phi$ is a phase; $r$ is nonlinearity measure; $f=\left(1-r^{2}\right)^{0.5}$ is a dimensionless factor that ensures the free stream velocity amplitude equal to $u_{w}$.

The waves shape is characterized by the asymmetric velocity index $R_{v}=u_{\max } /\left(u_{\max }-u_{\min }\right)$ and the dimensionless acceleration asymmetry index $\beta_{i}=1-T_{a i} / T_{i}$. Here $u$ is the flow velocity; subscript $(i=$ $c, t)$ denotes for crest or trough with $T_{i}$ being the half wave period (s); $T_{a i}$ is the time from the flow reversal to the maximum velocity at each half cycle (Fig.2). For the pure skewed oscillatory flow, the velocity profile is asymmetric between two half cycles with $u_{\max }$ being larger than $u_{\min }$, hence $R_{v}>0.5$ but $\beta_{\mathrm{i}}=0.5$ because $\mathrm{T}_{\mathrm{ai}}=0.5 T_{i}$ (Fig 1a). Analogously, under the pure asymmetric oscillatory flows, the horizontal velocity is symmetric with respect to horizontal axis (Fig 1c), thus $R_{v}=0.5$; however, $\beta_{c}$ is larger than 0.5 and $\beta_{t}$ is smaller 0.5 because $T_{a c}<0.5 T_{c}$ and $T_{a t}>0.5 T_{t}$ (Fig 1c). On the other hand, mixed skewed-asymmetric flows are characterized by both $R_{v}$ and $\beta_{c}$ being larger than 0.5 (Fig 1b).

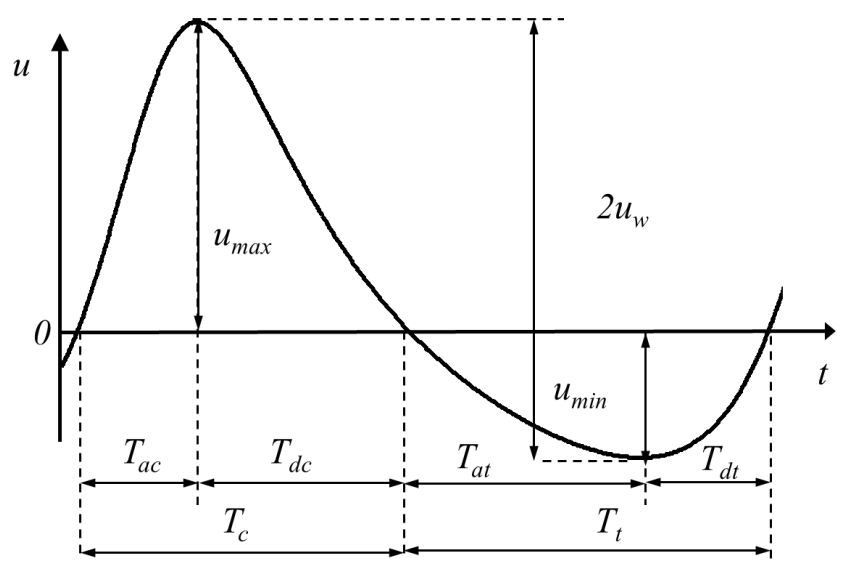

Figure 2. Definition sketch of a velocity profile

In total, 35 experiments comprise the net sand transport rate measurements for both fine sand $\left(d_{50}=\right.$ $0.16 \mathrm{~mm})$ and coarse sand $\left(d_{50}=0.3 \mathrm{~mm}\right)$ under three types of wave shapes, namely, pure skewed flows $\left(R_{v}=0.6, \beta_{c}=0.5\right)$, pure asymmetric flows $\left(R_{v}=0.5, \beta_{\mathrm{c}}=0.65\right)$ and the combined skewed-asymmetric oscillatory flows $\left(R_{v}=0.6 \& 0.55, \beta_{\mathrm{c}}=0.65 \& 0.6\right)$. Experimental conditions were listed in Table 1 , in which $\theta_{\mathrm{i}}(i=c, t)$ is the representative Shields parameter computed with separate friction factors for the wave crest and trough following the similar approach by Dong et al.(2013): 


$$
\begin{aligned}
& \theta_{i}=\frac{f_{w i} u_{i}^{2}}{2 s g d_{50}} \\
& u_{i}^{2}=\frac{2}{T_{i}} \int_{0}^{T_{i}} u^{2}(t) d t \\
& f_{w i}= \begin{cases}0.00251 \exp \left[5.21\left(\frac{X_{i} a}{k_{s}}\right)^{-0.19}\right] & \text { for } \frac{X_{i} a}{k_{s}}>1.587 \\
0.3 & \text { for } \frac{X_{i} a}{k_{s}} \leq 1.587\end{cases} \\
& a=\frac{u_{\sqrt{2} r m s} T}{2 \pi} ; X_{i}=\left(\frac{4 T_{a i}}{T}\right)^{2} \\
& u_{\sqrt{2} r m s}^{2}=\frac{2}{T} \int_{0}^{T} u^{2}(t) d t \\
& k_{s}= \begin{cases}2.5 d_{50}+5 d_{50} \theta_{\sqrt{2} \mathrm{rms}} & \text { for } d_{50} \geq 0.2 \mathrm{~mm} \\
2.5 d_{50}+10 d_{50} \theta_{\sqrt{2} \mathrm{rms}} & \text { for } d_{50} \leq 0.15 \mathrm{~mm} \\
2.5 d_{50}+\left[10-\frac{5\left(d_{50}-0.15\right)}{0.05}\right] \theta_{\sqrt{2} \mathrm{rms}} & \text { for } 0.15 \leq d_{50} \leq 0.20 \mathrm{~mm}\end{cases}
\end{aligned}
$$

where $s=\left(\rho_{\mathrm{s}}-\rho\right) / \rho$ with $\rho$ and $\rho_{\mathrm{s}}$ are the water and sediment density, respectively. $g=9.8 \mathrm{~m} / \mathrm{s}^{2}$ is gravity acceleration; $d_{50}$ is mean grain size. $\theta_{2 \text { rms }}$ is skin Shields parameter computed with $k_{s}=2.5 d_{50}$ and the equivalent sinusoidal velocity $u_{2 \text { rrms. }}$. The parameter $X_{i}$ takes into account an imbalance of the bed shear stress between each half cycle due to the flow acceleration (Dong et al., 2013; Nielsen, 2006; Silva et al., 2006; Van der A et al., 2010b; Watanabe and Sato, 2004)

Phase lag parameter, $p_{i}$, represents for the phase lag between suspended sand concentration and flow velocity. If the phase lag is significant $\left(p_{i}>1\right)$, part of the sand raised up in this half cycle cannot reach the bottom and can be transported in the next half cycle. The phase lag parameter is computed as the ratio between the sheetflow layer thickness, $\delta_{\mathrm{s}, \mathrm{i}}$, and the settling distance as follows (DohmenJanssen et al., 2001; Dong et al., 2013):

$$
\begin{gathered}
p_{i}=\frac{\delta_{s, i}}{w_{h s} T_{d i}} \\
d_{50}= \begin{cases}13 \theta_{i} & \text { for } d_{50} \geq 0.2 \mathrm{~mm} \\
22 \theta_{i} & \text { for } d_{50} \leq 0.15 \mathrm{~mm} \\
{\left[22-\frac{9\left(d_{50}-0.15\right)}{0.05}\right] \theta_{i}} & \text { for } 0.16<d_{50}<0.2 \mathrm{~mm}\end{cases}
\end{gathered}
$$

Average hindered settling velocity $w_{h s}$ is computed by assuming that the center of sheetflow layer is at the top of pick up layer. This elevation corresponds to the boundary between the pick-up layer where the concentrations are in anti-phase with the main flow and the upper sheetflow layer where the concentrations tend to be in phase with the main flow. The sand concentration at this elevation is found more or less $600 \mathrm{~g} / 1$ (Dohmen-Janssen et al., 2001). Therefore, the hindered settling velocity under this 
sand concentration is computed following Nielsen (1992) with $n=4$, which results $w_{h s}=0.36 w_{0}$. Here, $w_{0}$ is free settling velocity at still water $\left(w_{0}=0.018\right.$ and $0.043 \mathrm{~m} / \mathrm{s}$ for sand size of $0.16 \mathrm{~mm}$ and $0.30 \mathrm{~mm}$, respectively).

Flatbed forms were observed in all the cases that assure the sheetflow regime. Experimental processes were recorded by a high speed video camera (400frames/s) and then image analysis technique was applied to reproduce the information on sand transport movements through analyzing brightness of captured images. The net transport rates, $q_{\mathrm{s}}$, were estimated on the basis of sand mass difference in two halves of the tunnel after an experimental duration $\Delta t$ :

$$
q_{s}=\left(\Delta M_{o n}-\Delta M_{o f f}\right) /\left(2 b \rho_{s} \Delta t\right)
$$

where $b$ is the width of test section; $\Delta M_{\mathrm{on}}, \Delta M_{\mathrm{off}}$ is the difference in the sand mass on the onshore and offshore side before and after experiment, respectively

\begin{tabular}{|c|c|c|c|c|c|c|c|c|c|c|c|c|}
\hline Case & $\begin{array}{l}\mathrm{T} \\
\text { (s) }\end{array}$ & $\begin{array}{l}u_{\max } \\
(\mathrm{m} / \mathrm{s})\end{array}$ & $\begin{array}{l}u_{\min } \\
(\mathrm{m} / \mathrm{s})\end{array}$ & $\mathrm{u}_{\sqrt{2} \mathrm{rms}}$ & $R_{\mathrm{v}}$ & $\beta_{c}$ & $\begin{array}{l}d_{50} \\
(\mathrm{~mm})\end{array}$ & $\theta_{c}$ & $\theta_{\mathrm{t}}$ & $\mathrm{p}_{\mathrm{c}}$ & $\mathrm{p}_{\mathrm{t}}$ & $\begin{array}{c}\mathrm{q}_{\mathrm{s}} \\
\left(\mathrm{mm}^{2} / \mathrm{s}\right)\end{array}$ \\
\hline W1 & 3 & 1.2 & 0.8 & 0.95 & 0.6 & 0.65 & 0.16 & 1.10 & 3.31 & 0.43 & 1.31 & -56.6 \\
\hline W2 & 3 & 1.44 & 0.96 & 1.14 & 0.6 & 0.65 & 0.16 & 1.90 & 4.60 & 0.73 & 1.85 & -48.0 \\
\hline W3 & 3 & 1.68 & 1.12 & 1.33 & 0.6 & 0.65 & 0.16 & 0.35 & 1.78 & 0.14 & 0.69 & -23.2 \\
\hline W4 & 3 & 0.96 & 0.64 & 0.76 & 0.6 & 0.65 & 0.16 & 0.56 & 4.12 & 0.25 & 1.56 & -166.4 \\
\hline W5 & 3 & 1.2 & 0.8 & 0.98 & 0.6 & 0.5 & 0.16 & 0.02 & 1.86 & 0.01 & 0.64 & -81.8 \\
\hline W6 & 3 & 0.96 & 0.64 & 0.78 & 0.6 & 0.5 & 0.16 & 1.54 & 6.40 & 0.63 & 2.49 & -181.4 \\
\hline W7 & 3 & 1.44 & 0.96 & 1.18 & 0.6 & 0.5 & 0.16 & 0.65 & 3.43 & 0.26 & 1.90 & -68.7 \\
\hline W8 & 3 & 0.97 & 0.97 & 0.94 & 0.5 & 0.65 & 0.16 & 1.75 & 5.33 & 0.62 & 3.00 & -23.1 \\
\hline W9 & 3 & 0.77 & 0.77 & 0.75 & 0.5 & 0.65 & 0.16 & 0.03 & 1.57 & 0.01 & 0.78 & -64.7 \\
\hline W10 & 3 & 1.16 & 1.16 & 1.13 & 0.5 & 0.65 & 0.16 & 1.84 & 5.22 & 0.65 & 2.95 & -17.7 \\
\hline W11 & 5 & 1.2 & 0.8 & 0.95 & 0.6 & 0.65 & 0.16 & 0.03 & 1.57 & 0.01 & 0.78 & -84.4 \\
\hline W12 & 5 & 1.44 & 0.96 & 1.14 & 0.6 & 0.65 & 0.16 & 0.08 & 1.54 & 0.06 & 0.43 & -83.3 \\
\hline W13 & 5 & 0.96 & 0.64 & 0.76 & 0.6 & 0.65 & 0.16 & 0.51 & 2.39 & 0.30 & 0.70 & -156.2 \\
\hline W14 & 6 & 1.2 & 0.8 & 0.95 & 0.6 & 0.65 & 0.16 & 0.99 & 3.08 & 0.54 & 0.93 & -144.5 \\
\hline W15 & 5 & 1.2 & 0.8 & 0.98 & 0.6 & 0.5 & 0.16 & 0.09 & 1.09 & 0.08 & 0.28 & -43.2 \\
\hline W16 & 5 & 1 & 1 & 0.97 & 0.5 & 0.65 & 0.16 & 0.55 & 1.53 & 0.40 & 0.42 & -44.6 \\
\hline W17 & 5 & 0.8 & 0.8 & 0.78 & 0.5 & 0.65 & 0.16 & 1.33 & 2.09 & 0.87 & 0.58 & -98.6 \\
\hline W18 & 6 & 0.8 & 0.8 & 0.78 & 0.5 & 0.65 & 0.16 & 4.88 & 1.45 & 3.73 & 1.60 & -67.7 \\
\hline W19 & 7 & 0.8 & 0.8 & 0.78 & 0.5 & 0.65 & 0.16 & 7.23 & 2.13 & 5.53 & 2.35 & -151.3 \\
\hline W20 & 6 & 0.96 & 0.64 & 0.76 & 0.6 & 0.65 & 0.16 & 10.1 & 2.97 & 7.76 & 3.27 & -149.5 \\
\hline W21 & 7 & 0.96 & 0.64 & 0.76 & 0.6 & 0.65 & 0.16 & 3.05 & 0.91 & 2.33 & 1.00 & 21.3 \\
\hline W22 & 7 & 1 & 1 & 0.97 & 0.5 & 0.65 & 0.16 & 4.01 & 1.83 & 3.94 & 1.38 & -105.8 \\
\hline W23 & 3 & 1.2 & 0.8 & 0.95 & 0.6 & 0.65 & 0.30 & 2.51 & 1.15 & 2.46 & 0.87 & -31.2 \\
\hline W24 & 5 & 1.2 & 0.8 & 0.95 & 0.6 & 0.65 & 0.30 & 5.93 & 2.70 & 5.83 & 2.04 & -200.5 \\
\hline W25 & 5 & 1.44 & 0.96 & 1.14 & 0.6 & 0.65 & 0.30 & 3.22 & 2.11 & 2.10 & 2.59 & 73.1 \\
\hline W26 & 5 & 1.2 & 0.8 & 0.97 & 0.6 & 0.6 & 0.30 & 1.98 & 1.30 & 1.29 & 1.60 & 49.4 \\
\hline W27 & 5 & 1.44 & 0.96 & 1.16 & 0.6 & 0.6 & 0.30 & 5.10 & 3.31 & 3.32 & 4.06 & 77.9 \\
\hline W28 & 5 & 1.21 & 0.99 & 1.06 & 0.55 & 0.65 & 0.30 & 3.85 & 1.23 & 1.77 & 0.81 & 61.4 \\
\hline W29 & 5 & 1.43 & 1.17 & 1.25 & 0.55 & 0.65 & 0.30 & 5.68 & 1.80 & 2.61 & 1.19 & 53.4 \\
\hline W30 & 5 & 1.2 & 0.8 & 0.98 & 0.6 & 0.5 & 0.30 & 2.42 & 0.77 & 1.11 & 0.51 & 46.1 \\
\hline W31 & 5 & 1.2 & 1.2 & 1.16 & 0.5 & 0.65 & 0.30 & 3.55 & 1.16 & 1.36 & 0.64 & 68.3 \\
\hline W32 & 5 & 1.4 & 1.4 & 1.36 & 0.5 & 0.65 & 0.30 & 3.26 & 1.52 & 1.92 & 0.69 & -28.9 \\
\hline W33 & 5 & 1.4 & 0.93 & 1.18 & 0.6 & 0.5 & 0.30 & 2.75 & 1.88 & 1.08 & 1.38 & 105.0 \\
\hline W34 & 3 & 1.2 & 1.2 & 1.16 & 0.5 & 0.65 & 0.30 & 1.73 & 1.18 & 0.68 & 0.87 & 37.3 \\
\hline W35 & 3 & 1.2 & 0.8 & 0.98 & 0.6 & 0.5 & 0.30 & 1.61 & 1.12 & 0.53 & 0.68 & 20.3 \\
\hline
\end{tabular}

\section{Results and discussions}

The net transport rate measurements for different shaped flows with $T=3$ and 5 s were displayed in Fig. 3 with distinction being made for fine sand cases $\left(d_{50}=0.16 \mathrm{~mm}\right.$, Fig. $\left.3 \mathrm{a}\right)$ for coarse sand cases $\left(d_{50}\right.$ $=0.30 \mathrm{~mm}$, Fig. $3 \mathrm{~b}$ ). Experiments with fine sand (Fig.3a) shows that with increasing oscillatory velocities, $u_{\max }$, the onshore sand transport rates measured under the pure asymmetric oscillations $\left(R_{v}\right.$ 
$\left.=0.5 ; \beta_{c}=0.65\right)$ are also increasing in both $3 \mathrm{~s}$ and $5 \mathrm{~s}$ wave periods. In contrast, offshore sand movements were observed under the pure skewed oscillatory flows $\left(R_{v}=0.6 ; \beta_{c}=0.5\right)$ with magnitudes increase with increasing $u_{\max }$. This is identical to prior researches on pure velocity-skewed flows (Ahmed and Sato, 2003; Dibajnia and Watanabe, 1992; O'Donoghue and Wright, 2004a; Ribberink and Chen, 1993) and asymmetric oscillations (Van der A et al., 2010a; Watanabe and Sato, 2004). For the combined skewed-asymmetric wave (mixed shape; $R_{v}=0.6 ; \beta_{c}=0.65$ ) the measured net transport rates located between these ranges. This implies that the acceleration asymmetry effects (onshore transport) were partially compensated by velocity asymmetry effects (offshore transport). This so-called "cancelling effect" was also observed for the coarse sand under short wave period $(T=3 \mathrm{~s})$ as the net transport rates measured for mixed shape is between the measured values for the skewed velocity and the asymmetric flows (see Fig.3b, solid symbols). However, for the longer wave period ( $T=5 \mathrm{~s}$ ), it is found that the net transport rates for mixed shapes were $50 \%$ higher than that of the skewed and asymmetric flows (Fig. 3b, open symbols).
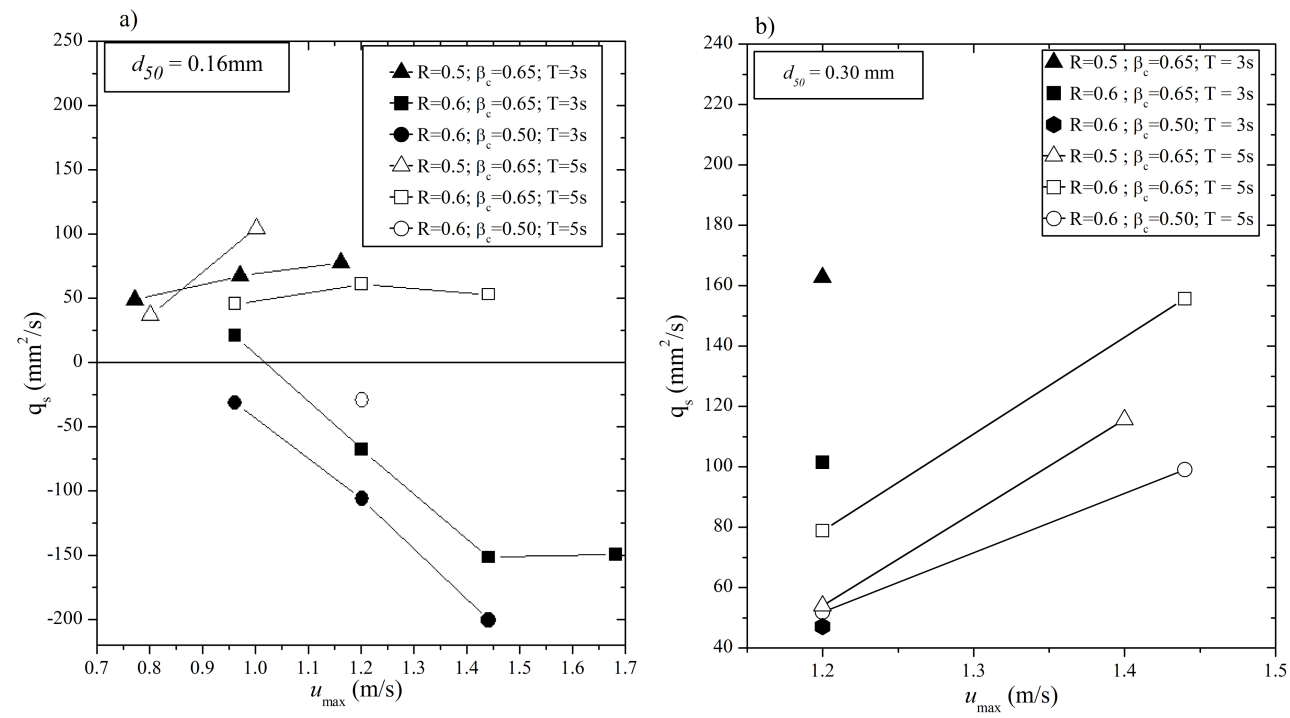

Figure 3. Net transport rate under pure waves for:a) very fine sand and b) medium sand

The sand transport mechanism could be explained by the concept of bed shear stress (or Shields parameter) and phase lag parameters. For example, the second row (left to right) in Fig.4 depicts the instantaneous normalized brightness distribution of fine sand $\left(d_{50}=0.16 \mathrm{~mm}\right)$ under experimental cases $\mathrm{W} 5, \mathrm{~W} 1$ and $\mathrm{W} 10$ respectively (all with $u_{\max }=1.2 \mathrm{~m} / \mathrm{s}$ and $T=3 \mathrm{~s}$ ). For these cases, the onshore bed shear stress is considerably larger than that of trough cycle, (see computed $\theta_{c}$ and $\theta_{t}$ in Table 1). Nevertheless, large offshore net transport rate measurements for pure skewed and skewed-asymmetric flows were observed (solid symbols in Fig.3a). From the brightness distribution, it is clear that lots of sands still remain in suspension at flow reversal in both half cycles $\left(p_{i}>1\right)$. However, computed phase lag parameters for skewed and skewed-asymmetric flows show that phase lag parameters in crest cycle $\left(p_{c}\right)$ are sufficiently larger than those in trough cycle $\left(p_{t}\right)$. Therefore, they might compensate the bed shear stress and transport sand to the offshore direction. In addition, in comparison with the pure skewed flows, the offshore sand transport rate measured with the skewed-asymmetric flow is attributed to be smaller; probably due to larger $\theta_{c}$ and smaller $p_{c}$. For the asymmetric flows, on the other hand, phase lag in the trough cycle is larger than in crest cycle. Thus, together with the higher bed shear stress in crest cycle, it tends to enhance onshore transport rate.

As depicted from Fig. $3 \mathrm{~b}$, the "cancelling effect" is also observed for coarser sand $\left(d_{50}=0.30 \mathrm{~mm}\right)$ under short wave period $(T=3 \mathrm{~s})$, but their transport mechanism quite differ from that of fine sand. It is obviously seen from brightness distribution (two left columns in row 3 of Fig.4) under the pure skewed velocity and the mixed shape flows, the "exchange process of suspended sand from crest to trough" is about significant (computed $p_{c} \approx 0.9$ for both two cases W35 and W23). However, the bed shear stress in the crest cycle $\left(\theta_{c}\right)$ is much larger than that of trough cycle $\left(\theta_{t}\right)$. For instance, the indicator $\theta_{c} / \theta_{t}$ is 3.5 for case W23 whereas it is about 2.2 for case W35. Therefore, sand is still dominantly transported to onshore direction and the net sand transport rate for the mixed shape (case W23) is consequently larger due to larger $\theta_{c} / \theta_{t}$. In contrast, the further onshore enhancement found with the pure asymmetric flow 
(case W34 in comparison with case W23) is probably caused by the significant phase lag during the trough cycle $\left(p_{t} \approx 0.9\right)$. Thus, part of sand entrained in the trough cycle is transported to onshore direction and contributes to an increase of the onshore net transport rate.

Small phase lag parameters $\left(p_{i}\right.$ is much smaller than 0.9 ) computed in Table 1 (cases W30, W24 and W31) agree well with measured brightness distributions of coarse sand for $5 \mathrm{~s}$ wave period (bottom row of Fig. 4). This suggests that net sand transport rate is mainly influenced by the bed shear stress. It is noticed that the ratio $\theta_{c} / \theta_{t}$ for the skewed-asymmetric flow (case W24) is about 1.5 to 2.2 larger than that of the pure skewed and asymmetric flows. Subsequently, under this condition, the onshore enhancement for the mixed shape flow is expected to happen.
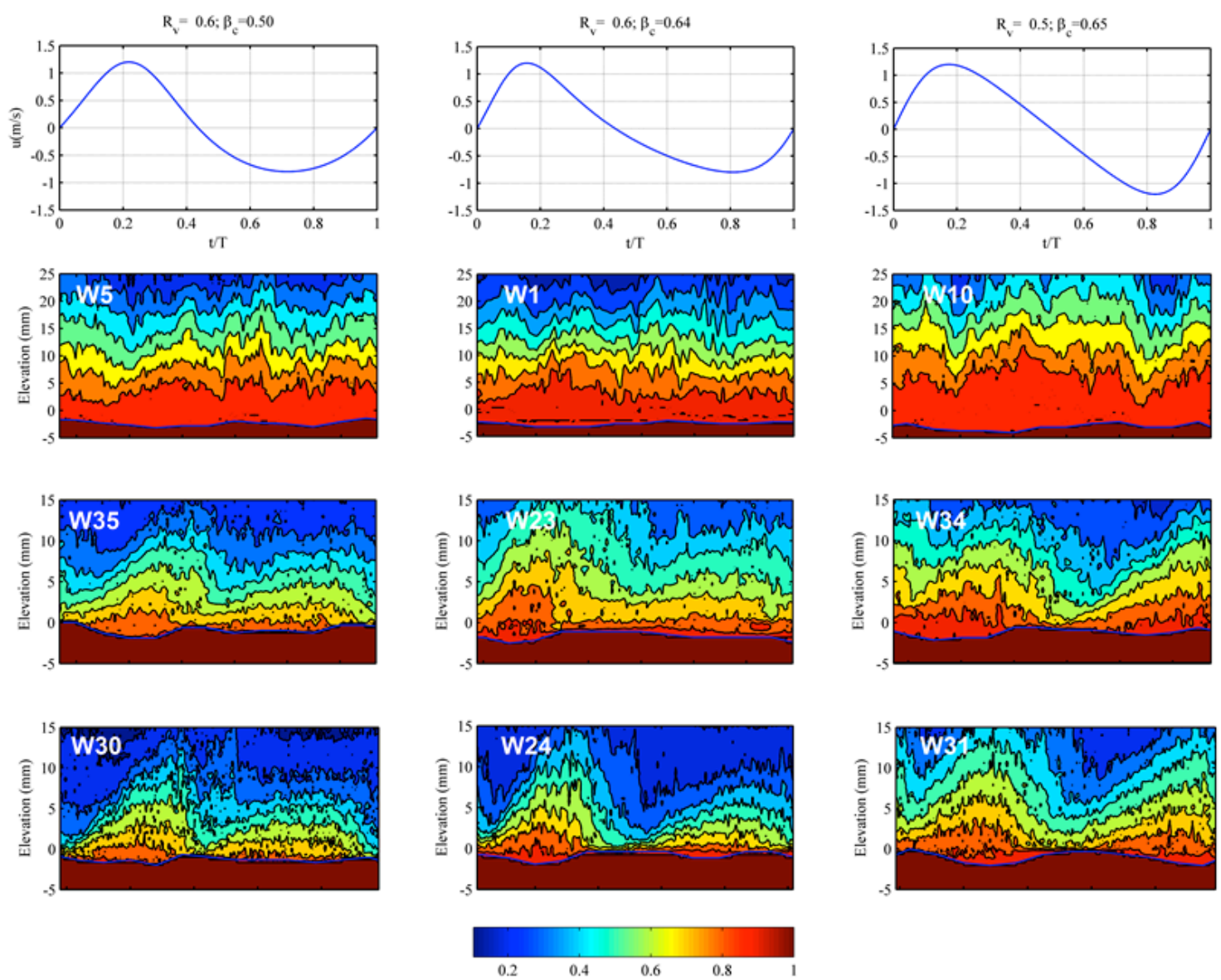

Figure 4. Normalized temporal brightness distribution for (from left to right) pure velocity asymmetric wave, the mixed wave shape and the pure acceleration asymmetric wave. From top to bottom are flow velocity with umax $=1.2 \mathrm{~m} / \mathrm{s}$ (first row), brightness distribution of fine sand with $T=3 \mathrm{~s}$ (second row), coarse sand with $T=$ $3 \mathrm{~s}$ (third row) and coarse sand with $\mathrm{T}=5 \mathrm{~s}$ (fourth row).

\section{SHEETFLOW SAND TRANSPORT MODELLING}

Many sand transport models exist to predict the net sand transport rates under sheetflow regime for both linear/nonlinear as well as regular/irregular wave conditions. In general, the models can be classified as empirical/conceptual transport formulae (e.g., quasi-steady model and semi-unsteady models) and more complex, theoretical and sophisticated bottom boundary layer models (e.g., one dimensional vertical approximation models or two-phase flow models). From the practical point of view, the computational demands for theoretical models are high and it is difficult to apply them in conjunction with morphological models. The practical models (quasi-steady or semi-unsteady models), on the other hand, based on much simple expressions so that they require less computation time and thus their applicability is obvious.

Quasi-steady models are based on the assumption that the sand transport reacts immediately with flow conditions (Bailard, 1981; Drake and Calantoni, 2001; Gonzalez-Rodriguez and Madsen, 2007; Hoefel and Elgar, 2003; Nielsen, 2006; Ribberink, 1998). The instantaneous sediment transport rate is 
directly computed from the instantaneous bed shear stress and the net transport rate is estimated by taking the time average transport rate over one wave cycle. Some researchers proposed a simple extension to the energetics formula of Bailard (1981) to include a contribution to the period-averaged net transport caused by acceleration skewness (Drake and Calantoni, 2001; Hoefel and Elgar, 2003). Others take into account the "acceleration effects" of acceleration asymmetric waves through introducing the velocity gradient (Nielsen, 2006), or the time lag between bed shear stress and bed velocity (Gonzalez-Rodriguez and Madsen, 2007). However, for this kind of model, the phase lag effects (i.e., sand entrainment and delayed settling of the suspended sand particles, Dibajnia and Watanabe, 1992; Dohmen-Janssen et al., 2002) were neglected. Thus, it is only suitable to apply the quasi-steady approach for the conditions under which settling time of entrained sand particle is much smaller than the wave period.

In order to account for the time lag between suspended sand and the flow, Dibajnia and Watanabe (1992) and its subsequent models (Dibajnia et al., 2001, here after refered as DW; Dibajnia and Watanabe, 1998) considered the exchanged amount of sand transport in two successive half cycles. Later, Watanabe and Sato (2004) introduced the acceleration asymmetry index into a modified DW model to takes into account the "acceleration effects" observed in their experiments conducted with the uniform sands (size of 0.20 and $0.74 \mathrm{~mm}$ ) under the acceleration asymmetric waves. Other DW type models accounted the effect of acceleration skewness through using different friction factors (bed shear stress) at each half wave cycle. (Dong et al., 2013; Silva et al., 2006; Van der A, 2010)

In this part the results of different practical sand transport models will be compared with the measurements. As indicated above, quasi-steady sand transport formulations have considerable shortcomings in comparison with the semi-unsteady model. The quasi-steady models could not account for the phase lag effects which are observed to be important especially for the very fine sand and short wave period experiments in present study as well as prior experiments (Ahmed and Sato, 2003; Dohmen-Janssen et al., 2002; O'Donoghue and Wright, 2004b; Van der A et al., 2010a). Of particular emphasis within this study are the effects of velocity and acceleration skewness on sediment transport. Thus verification has been made for some existing semi-unsteady models that considered the acceleration skewness effects, namely the Silva et al, (2006) model, the SANTOSS model (Van der A et al., 2010b) and the newly developed model by Dong et al. (2013). These three models were based on the original concept proposed by Dibajnia and Watanabe (1992). It is noticed that the model of Watanabe and Sato (2004) also accounts for the acceleration skewness effects. However, it was found that this model failed to deliver an accurate prediction for fine sands $\left(d_{50}<0.15 \mathrm{~mm}\right)$ and for combined oscillatory flows-strong currents condition (Dong et al., 2013). The reason is due to the inappropriate estimates of the representative suspension height in their model, which was derived from an energetic balance concept (Dong et al., 2013). Besides that, due to space limitation, we did not aim to compare all DW type models in this paper. In fact, three models were considered in this study because they corrected the uncertainty of the representative suspension height and thus the phase lag parameter in DW concept through calibrating with experiments. Existing data from different experimental facilities around the world were collected to create a comprehensive data set used for model verification. Behavior and limitation of these models will also be discussed.

Silva et al (2006) - SI06 model

The Silva et al. (2006) formulation is a semi-unsteady based on the original formulation of Dibajnia and Watanabe (1992). The net transport rate is given by:

$$
\frac{q_{s}}{\sqrt{(s-1) g d_{50}^{3}}}=\alpha_{1} \Gamma^{\alpha_{2}} \frac{\Gamma}{|\Gamma|}
$$

where $\alpha_{1}=3.2$ and $\alpha_{2}=0.55$ are the experimental constants, and

$$
\Gamma=\frac{u_{c} T_{c}\left(\Omega_{c}^{3}+\Omega_{c}^{\prime 3}\right)-u_{t} T_{t}\left(\Omega_{t}^{3}+\Omega_{t}^{\prime 3}\right)}{2\left(u_{c} T_{c}+u_{t} T_{t}\right)}
$$

$u_{i}(i=c, t)$ is the equivalent sinusoidal velocity amplitude. The amounts of entrained sediment $\Omega_{i}$ and $\Omega^{\prime}{ }_{i}$ are calculated by the Shields parameters: 


$$
\begin{gathered}
\Omega_{i}=\left(\theta_{i}-\theta_{c r}\right) \min \left(1, \omega_{c r} / \omega_{i}\right) ; \Omega^{\prime}{ }_{i}=\left(\theta_{i}-\theta_{c r}\right) \max \left(0,1-\omega_{c r} / \omega_{i}\right) \\
\omega_{i}=\frac{1}{2} \frac{u_{i}^{2}}{(s-1) g 2\left(T_{i}-T_{a i}\right) w_{o}} \quad(i=c, t) \\
\theta_{i}=\frac{1}{2} \frac{f_{c w i} u_{i}^{2}}{(s-1) g d_{50}} \quad(i=c, t)
\end{gathered}
$$

The effect of acceleration skewness on the Shields parameter is introduced through the wavecurrent friction factor $f_{\text {cwi }}$. The wave-current friction factors are calculated following Madsen and Grant (1976)as:

$$
\begin{gathered}
f_{c w i}=\alpha_{c} f_{c}+\left(1-\alpha_{c}\right) f_{w i} \\
\alpha_{c}=\frac{u_{m}}{u_{w}^{*}+u_{m}}
\end{gathered}
$$

with $u_{m}$ is the current velocity. In the positive half cycle $u_{w}^{*}=u_{\max }$ while in the negative half cycle $u_{w}^{*}=u_{\text {min }}$. The current friction factor $f_{c}$ is computed assuming a logarithmic vertical velocity profile:

$$
f_{c}=2\left[\frac{0.4}{\ln \left(z_{u m} / z_{o}\right)}\right]^{2}
$$

where $z_{u m}$ is the elevation where $u_{m}$ is specified and $z_{o}=k_{s} / 30$ is the level where velocity assumed to be zero. The wave-related friction factor is calculated separately for the onshore and offshore cycle in similar way described in Eq.(4) but with the parameter $X_{i}=4 T_{a i} / T$ and the bed roughness is estimated as $k_{s}=2.5 d_{50}+5 d_{50} \theta_{\sqrt{2} r m s}$. Silva et al., (2006) have proposed an implicit adjustment of the parameter $\omega_{c r}$ by assuming that $\omega_{c r}$ is a function of the skin Shields parameter. Then the optimal values of $\omega_{c r}$ can be solved iteratively, considering to the minimum difference between the computed and the measured sand transport rates. Readers are referred to the original paper for the further description of the model.

Van der A et al (2010b) - SANTOSS model

The total net transport rate over wave cycle in SANTOSS model is estimated as:

$$
\frac{q_{s}}{\sqrt{(s-1) g d_{50}^{3}}}=\frac{\sqrt{\left|\theta_{c}\right|} T_{c}\left(\Omega_{c}+\frac{T_{c}}{2 T_{c u}} \Omega_{t}^{\prime}\right) \frac{\theta_{c}}{\left|\theta_{c}\right|}-\sqrt{\left|\theta_{t}\right|} T_{t}\left(\Omega_{t}+\frac{T_{t}}{2 T_{t u}} \Omega_{c}^{\prime}\right) \frac{\theta_{t}}{\left|\theta_{t}\right|}}{T} \text { (19) }
$$

In Eq.(19), the Shields parameter for oscillatory flow plus current is calculated as:

$$
\theta_{i}=\frac{1}{2} \frac{f_{c w i} u_{i r}\left|u_{i r}\right|}{(s-1) g d_{50}} \quad(i=c, t)
$$

with $u_{i r}$ is the representative velocity for each half wave cycle. As schematized in Fig.5, this velocity is calculated as:

$$
u_{c r}=\tilde{u}_{c r}+u_{m}
$$




$$
\begin{gathered}
u_{t r}=-\tilde{u}_{t r}+u_{m} \\
\tilde{u}_{i r}=\frac{\sqrt{2}}{2} \tilde{u}_{i} \quad(i=c, t)
\end{gathered}
$$

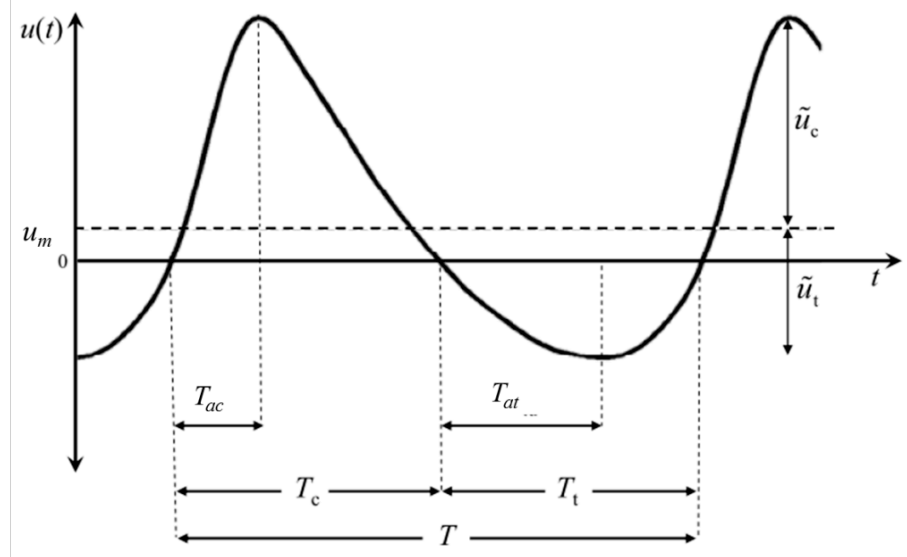

Figure 5. Schematic of wave input for SANTOSS model (Van der A et al.,2010b)

The friction factor for collinear wave and current, $f_{c w i}$, is also calculated following Madsen and Grant (1976) (Eq.16) with separate wave-related friction factors $f_{w i}$ estimated by Eq.(4) but with $X_{i}=$ $\left(2 T_{a i} / T\right)^{2}$. In addition, the bed roughness for wave and currents is calculated in similar way with Ribberink (1998) as follows:

$$
\begin{aligned}
& k_{s w}=\max \left\{d_{50}, d_{50}[\mu+6(\langle\theta\rangle-1)]\right\} \\
& k_{s m}=\max \left\{3 d_{90}, d_{50}[\mu+6(\langle\theta\rangle-1)]\right\}
\end{aligned}
$$

where $\langle\theta\rangle$ is the mean absolute Shields parameter given by

$$
\langle\theta\rangle=\frac{\frac{1}{2} f_{c}\left|u_{m}\right|^{2}}{(s-1) g d_{50}}+\frac{\frac{1}{4} f_{w} u_{w}{ }^{2}}{(s-1) g d_{50}}
$$

The parameter $\mu$ is introduced to create an increased roughness and sand load for fine sand conditions $\left(d_{50} \leq 0.15 \mathrm{~mm}\right)$ and results from calibration tests. For fine sands $\mu=6$ which linearly reduces to $\mu=1$ for medium and coarser sands $\left(\mathrm{d}_{50} \geq 0.20 \mathrm{~mm}\right)$.

The amounts of entrained sediment $\Omega_{i}$ and $\Omega^{\prime}{ }_{i}$ are estimated by:

$$
\Omega_{i}=q_{i} \min \left(1, p_{c r} / p_{i}\right) ; \Omega_{i}^{\prime}=q_{i} \max \left(0,1-p_{c r} / p_{i}\right)
$$

with the sand load $q_{i}$ is correlated with the Shields parameter as follows:

$$
q_{i}= \begin{cases}0 & \text { if }\left|\theta_{i}\right| \leq \theta_{c r} \\ m\left(\left|\theta_{i}\right|-\theta_{c r}\right)^{n} & \text { if }\left|\theta_{i}\right| \geq \theta_{c r}\end{cases}
$$

where the critical Shields number, $\theta_{c r}$ is calculated following Soulsby and Whitehouse (1997). $m=9.48$ and $n=1.2$ are the calibration coefficients. The phase lag parameter in SANTOSS model is computed as:

$$
p_{i}=\alpha_{s h} \frac{\delta_{s i}}{T_{i} w_{o}}
$$

where $\alpha_{s h}=8$ is the calibration coefficient; the sheetflow layer thickness, $\delta_{s i}$ is linearly correlated with the wave-related bed shear stress similar to Dohmen Janssen (1999): 
$\frac{\delta_{s, \max }}{d_{50}}= \begin{cases}13\left|\theta_{w i}\right| & \text { for } d_{50} \geq 0.20 \mathrm{~mm} \\ {\left[25+\left(10^{3} d_{50}-0.15\right) \frac{13-25}{0.2-0.15}\right]\left|\theta_{w i}\right|} & \text { for } 0.15<d_{50}<0.20 \mathrm{~mm} \mathrm{(30)} \\ 25\left|\theta_{w i}\right| & \text { for } d_{50} \leq 0.15 \mathrm{~mm}\end{cases}$

\section{Dong et al.(2013)'s formulation}

Dong et al. (2013) model is based on the concept of Watanabe and Sato (2004) model. The net transport rate over a wave cycle is calculated as:

$$
\begin{aligned}
& \varphi_{s}=\frac{q_{s}}{\sqrt{(s-1) g d_{50}^{3}}}=0.16 \frac{\sqrt{\theta_{c}} T_{c}\left(\Omega_{c}+2 \beta_{c} \Omega_{t}^{\prime}\right)-\sqrt{\theta_{t}} T_{t}\left(\Omega_{t}+2 \beta_{t} \Omega_{c}^{\prime}\right)}{T}(31) \\
& \left\{\begin{array}{l}
\omega_{i} \leq 1\left\{\begin{array}{l}
\Omega_{i}=q^{\prime \prime} \\
\Omega_{i}=0
\end{array}\right. \\
\omega^{\prime \prime}>1\left\{\begin{array}{l}
\Omega_{i}=q^{\prime \prime}{ }_{i} \frac{1}{\omega^{\prime \prime}} \\
\Omega_{i}{ }_{i}=q^{\prime}{ }_{i} \frac{\omega^{\prime \prime}-1}{\omega^{\prime \prime}}
\end{array}\right.
\end{array}\right. \\
& \omega^{\prime \prime}{ }_{i}=\gamma \frac{\delta_{s, i}}{2 \beta_{i} w_{o} T_{i}} \\
& \frac{\delta_{s i}}{d_{50}}=\left\{\begin{array}{lr}
13 k_{T i} \theta_{i} & \text { for } d_{50} \geq 0.2 \mathrm{~mm} \\
22 k_{T i} \theta_{i} & \text { for } d_{50} \leq 0.15 \mathrm{~mm} \\
{\left[22-\frac{9\left(d_{50}-0.15\right)}{0.05}\right] k_{T i} \theta_{i}} & \text { for } 0.16<d_{50}<0.2 \mathrm{~mm}
\end{array}\right. \\
& q^{\prime \prime}=\left\{\begin{array}{lll}
13 k_{T_{i}}\left(\theta_{i}-\theta_{c r}\right) & \text { for } & d_{50} \geq 0.20 \mathrm{~mm} \\
22 k_{T_{i}}\left(\theta_{i}-\theta_{c r}\right) & \text { for } & d_{50} \leq 0.15 \mathrm{~mm}(35) \\
{\left[22-\frac{9\left(d_{50}-0.15\right)}{0.05}\right] k_{T_{i}}\left(\theta_{i}-\theta_{c r}\right)} & \text { for } 0.16<d_{50}<0.20 \mathrm{~mm}
\end{array}\right.
\end{aligned}
$$

Herein, $\theta_{i}$ is the representative Shields parameter computed in a similar way described Eq.(2). It is noticed that for a combined wave-current flows, the representative velocity $u_{i}$ in Eq.(2) is calculated as:

$$
u_{i}^{2}=\frac{2}{T_{i}} \int_{0}^{T_{i}}\left(u(t)+u_{m}\right)^{2} d t
$$

and the separate wave-current friction factor $f_{c w i}$ can be calculated by Eqs.(16)-(18) with the bed roughness $k_{s}$ estimated by Eq.(7) with $u_{\sqrt{2} r m s}^{2}=\frac{2}{T} \int_{0}^{T}\left(u(t)+u_{m}\right)^{2} d t . \theta_{c r}=0.05$ is critical Shields parameter for onset of the initial movement; parameter $\gamma$ is calibrated with experiments: $\gamma=4$. $\delta_{s, i}$ is the 
sheetflow layer thickness. $k_{T i}=\left(T_{t} / T_{t, w}\right)^{0.5}$ is an intensive parameter which considering that the presence of superimposed currents may enlarge pick up time and hence increase the sheetflow layer thickness (Dong et al., 2013); $\beta_{i}$ is the velocity leaning index;

\section{Comparison between measurements and computations}

In the following we compare the measured net transport rates with the predicted net transport rates by three net sand transport rate models. The data set used to verify models in this study is the same with those described in Dong et al. (2013).

Model accuracy was determined using the percentage of prediction that falls within the factor of 2 (P2) and the root means square error (RMSE) between predictions and measurements, which was proposed by Ahmed and Sato (2003):

$$
\operatorname{RMSE}=\frac{\sqrt{\frac{1}{N} \sum_{n=1}^{N}\left|q_{\text {comp }}-q_{\text {meas }}\right|^{2}}}{\sqrt{\frac{1}{N} \sum_{n=1}^{N} q_{\text {meas }}^{2}}}
$$

where $q_{\text {comp }}$ and $q_{\text {meas }}$ are computed and measured net transport rates, respectively; $N$ is the number of experiments

Quantitative measures of the performance of each formulation are presented in Table 2. Furthermore, the comparison is further divided into fine sand $\left(\mathrm{d}_{50}<0.2 \mathrm{~mm}\right)$ and coarser sand $\left(\mathrm{d}_{50} \geq\right.$ $0.2 \mathrm{~mm}$ ). Performance scores for three models are quite similar for fine sands, however, predictions by Dong et al. model are in much better agreement with measurements than Silva et al and SANTOSS model. The best overall performance also comes from Dong et al model; meanwhile Silva et.al model gives the worst scores.

Looking into detail the development of the SI06 model, we found that the model did account for the uncertainty of the representative suspension height and the phase lag but through calibrating $\omega_{c r}$ with a limited dataset; for which some complex sand transport processes are maybe absent or not considered adequately. For example, the significant phase lag can even occur with coarse sand under short wave periods (see above experiments). These problems become clearer in Fig. 6 where the predictions by SI06 model were shown with distinction for short wave periods $(\mathrm{T}<5 \mathrm{~s})$ with large scattering and longer wave periods $(\mathrm{T} \geq 5 \mathrm{~s})$ with quite good predictions. The SANTOSS model provides an overall better prediction than SI06 model. However, analyzing the prediction data by SANTOSS model, it is found that large discrepancy with experiments still exists for short period cases as well as for some collinear wave-current cases (Fig.7). Indeed, the experimental coefficients in the SANTOSS model were calibrated mainly with relatively longer wave period $(\mathrm{T} \geq 5)$. Thus, similar to SI06 model, the model underestimates the phase lag effect for coarse sand under short wave case. The highest overall scores for Dong et.al model (Fig.8) is probably because it used a more appropriate estimation of the sheetflow layer thickness and hence better estimates of phase lag parameters. Furthermore, it was also calibrated over a wider range of experimental conditions. Thus, better agreement between measurements and predictions by the Dong et al. model can be expected.

\begin{tabular}{|c|c|c|c|c|c|c|c|}
\hline \multirow[t]{3}{*}{ Model } & \multirow[t]{3}{*}{ Clarification } & \multicolumn{4}{|c|}{ All } & \multirow{2}{*}{\multicolumn{2}{|c|}{ Overall }} \\
\hline & & \multicolumn{2}{|c|}{ Fine } & \multicolumn{2}{|c|}{ Coarse } & & \\
\hline & & RMSE & P2 (\%) & RMSE & P2 (\%) & RMSE & P2 (\%) \\
\hline \multirow[t]{2}{*}{ Silva et al } & Osc.flows & 0.44 & $73.8 \%$ & 1.04 & $42.4 \%$ & \multirow[t]{2}{*}{1.05} & \multirow[t]{2}{*}{48.9} \\
\hline & Osc.+currents & 0.57 & $64.0 \%$ & 1.12 & $41.4 \%$ & & \\
\hline \multirow[t]{2}{*}{ SANTOSS } & Osc.flows & 0.53 & $76.9 \%$ & 1.33 & $47.2 \%$ & \multirow[t]{2}{*}{0.97} & \multirow[t]{2}{*}{56} \\
\hline & Osc.+currents & 0.68 & $72.0 \%$ & 0.65 & $52.3 \%$ & & \\
\hline \multirow[t]{2}{*}{ Dong et al } & Osc.flows & 0.54 & $78.5 \%$ & 0.47 & $75.0 \%$ & \multirow[t]{2}{*}{0.5} & \multirow[t]{2}{*}{71.4} \\
\hline & Osc. + currents & 0.58 & $72.0 \%$ & 0.43 & $73.0 \%$ & & \\
\hline
\end{tabular}



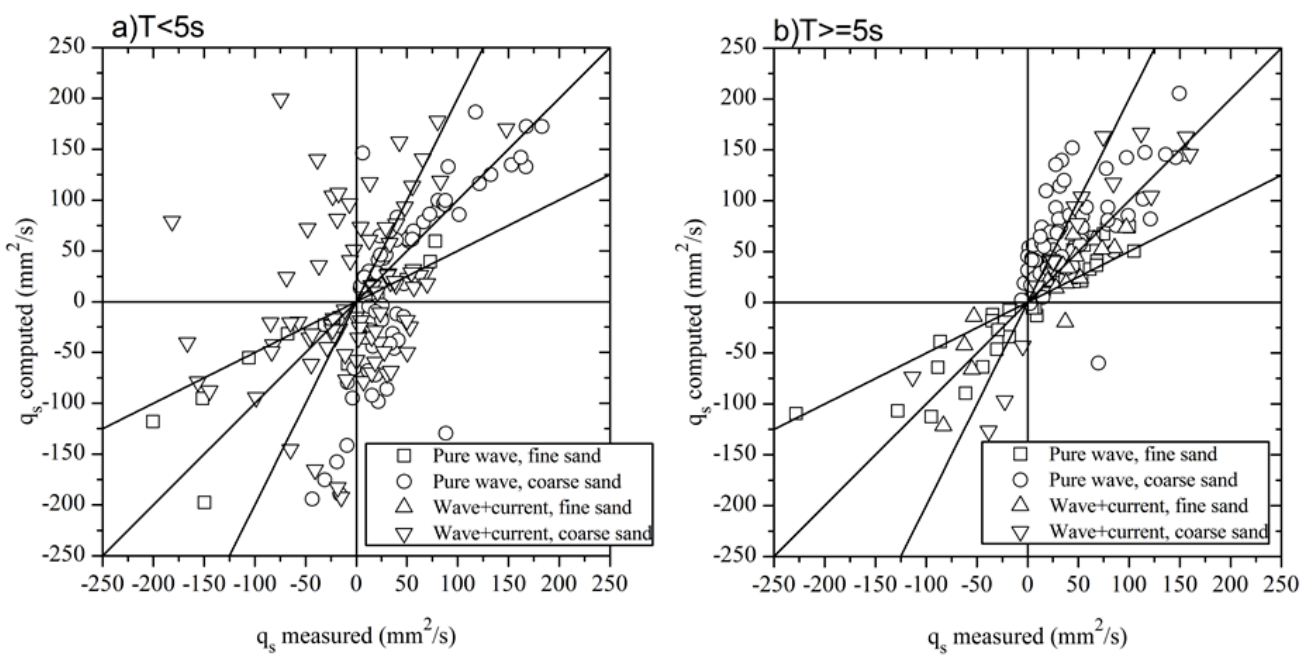

Figure 6. Net transport rates predicted by S106 model versus measurements for: a) short wave period $\mathrm{T}<5 \mathrm{~s}$ and b) long wave period $T \geq 5 \mathrm{~s}$
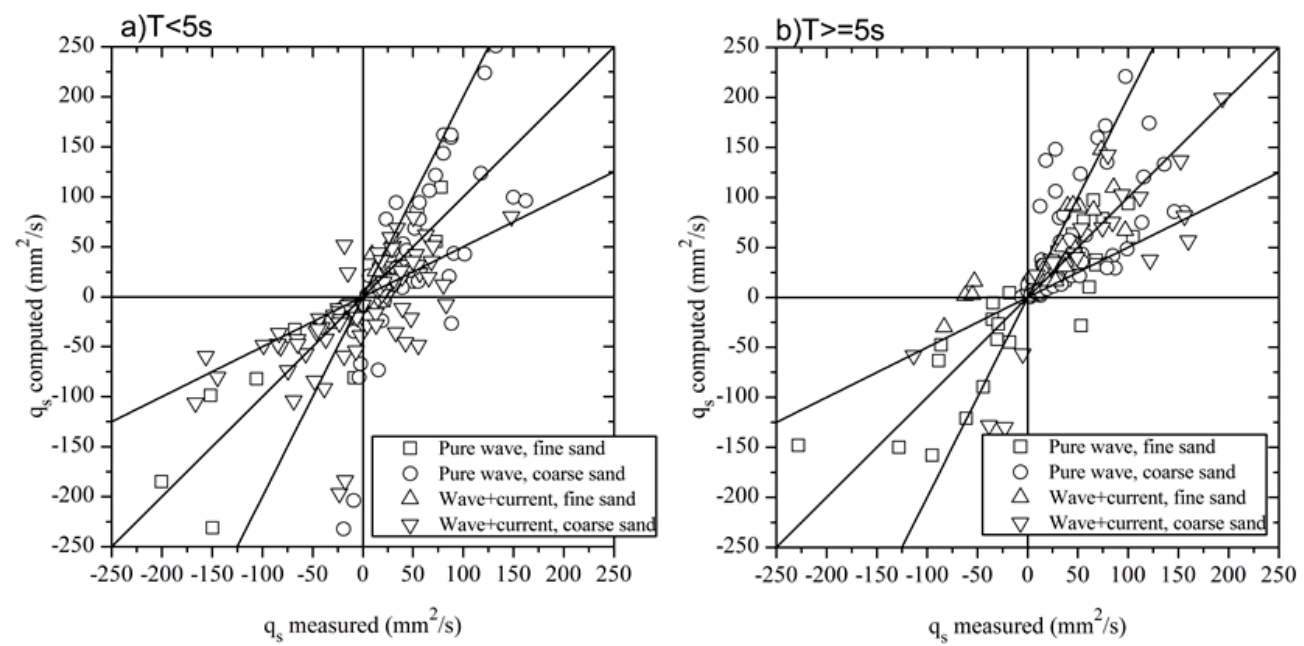

Figure 7. Net transport rates predicted by SANTOSS model versus measurements for: a) short wave period $T<5 s$ and $b$ ) long wave period $T \geq 5 s$

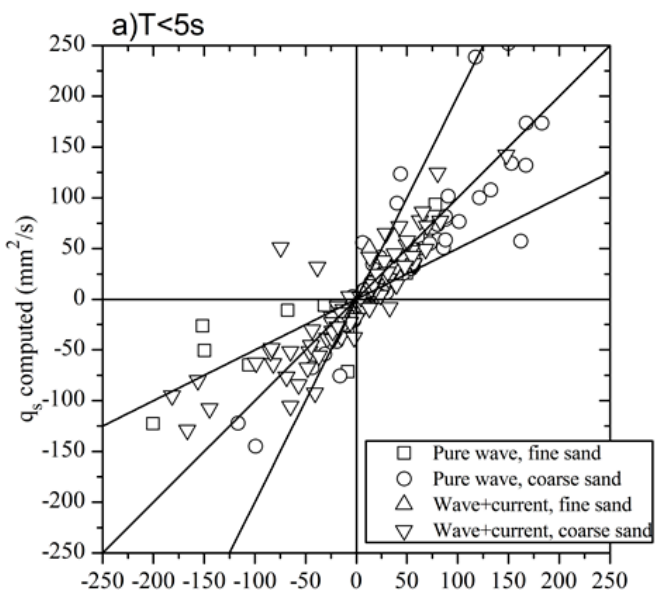

$\mathrm{q}_{\mathrm{s}}$ measured $\left(\mathrm{mm}^{2} / \mathrm{s}\right)$

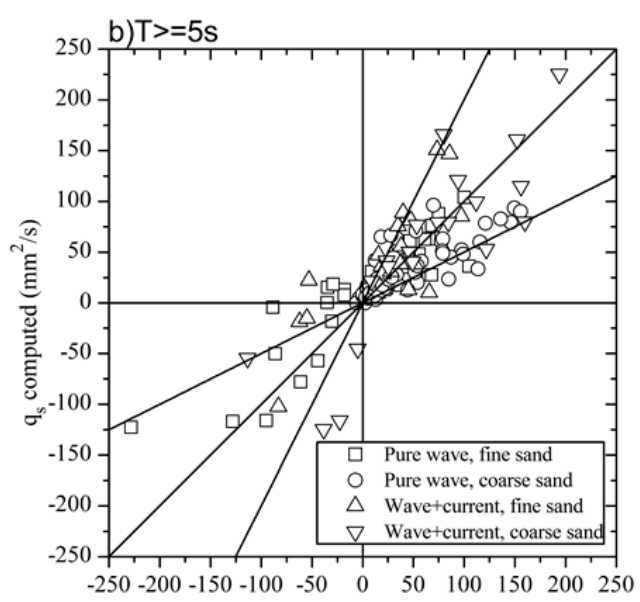

$\mathrm{q}_{\mathrm{s}}$ measured $\left(\mathrm{mm}^{2} / \mathrm{s}\right)$

Figure 8. Net transport rates predicted by Dong et al model versus measurements for: a) short wave period $T<5 s$ and $b$ ) long wave period $T \geq 5 s$ 


\section{CONCLUSION}

- A new experimental dataset were conducted using an Oscillatory flow Tunnel at the University of Tokyo allowing to investigate the behaviors of sheetflow sediment transport under skewedasymmetric oscillatory flows. So far, these experimental data are not available worldwide. These new experiments (35 tests) sufficiently extended the existing dataset used for model verification and development.

- Experimental results reveal that in most of the case with fine sand, the "cancelling effect", which balances the on-/off-shore net transport under pure asymmetric/skewed flows and results a moderate net transport, was developed for combined skewed-asymmetric oscillatory flows. However, under some certain conditions $(\mathrm{T}>5 \mathrm{~s})$ with coarse sands, the onshore sediment transport was enhanced by $50 \%$ under combined skewed-asymmetric flows.

- Sand transport mechanism was investigated by comparing the bed shear stress and the phase lag parameter for each half cycle. The "phase lag parameter" was modeled as the ratio between the sheetflow layer thickness and the settling distance. By analyzing the temporal brightness distribution at different elevations which corresponds to the distribution of suspended sand concentration, it is precisely found that phase lag is considered to be significant once it value exceeds 0.9. In such circumstances, the so-called "cancelling effect", will occur. In contrast, in cases phase lag is small; the bed shear stress plays a more fundamental role as it causes an onshore enhancement for mixed shaped flows

- A number of existing semi-unsteady sand transport formulations incorporating acceleration skewness effects have been tested against the comprehensive experimental data available to date. All three considered models, namely, Silva et al, SANTOSS and Dong et al. models performed well for fine sands. However, the latter provided much better predictions for coarse sands than the two formers. The poor performances of Silva et al and SANTOSS model for specific conditions have been pointed out due to an inadequate consideration of the phase lag effects in their models. Overall, Dong et al. (2013) formulation performs the best in predicting the measured net transport rates over a wide range of experimental conditions.

\section{REFERENCES}

Ahmed, A.S.M. and Sato, S., 2003. A sheetflow transport model for asymmetric oscillatory flows: Part i: Uniform grain size sediments. . Coastal Engineering Journal (JSCE), 45(3): 321-337

Bailard, J.A., 1981. An energetics total load sediment transport model for a plane sloping beach. Journal of Geophysical Research, 86.

Dibajnia, M., Moriya, T. and Watanabe, A., 2001. A representative wave model for estimation of nearshore local transport rate. Coastal Engineering Journal (JSCE), 43: 38.

Dibajnia, M. and Watanabe, A., 1992. Sheet flow under nonlinear waves and currents. Proceedings 23rd International Conference on Coastal Engineering, Venice Italy, p.^pp. 2015-2028.

Dibajnia, M. and Watanabe, A., 1998. Transport rate under irregular sheet flow conditions. Coastal Engineering, 35(3): 167-183.

Doering, J.C. and Bowen, A.J., 1995. Parametrization of orbital velocity asymmetries of shoaling and breaking waves using bispectral analysis. Coastal Engineering, 26(1-2): 15-33.

Dohmen-Janssen, C.M., Hassan, W.N. and Ribberink, J.S., 2001. Mobile-bed effects in oscillatory sheet flow. Journal of Geophysical Research, 106.

Dohmen-Janssen, C.M., Kroekenstoel, D.F., Hassan, W.N. and Ribberink, J.S., 2002. Phase lags in oscillatory sheet flow: Experiments and bed load modelling. Coastal Engineering, 46(1): 6187.

Dong, L.P., Sato, S. and Liu, H., 2013. A sheetflow sediment transport model for skewed-asymmetric waves combined with strong opposite currents. Coastal Engineering, 71(0): 87-101.

Drake, T.G. and Calantoni, J., 2001. Discrete particle model for sheet flow sediment transport in the nearshore. Journal of Geophysical Research, 106(C9): 19859-19868.

Gonzalez-Rodriguez, D. and Madsen, O.S., 2007. Seabed shear stress and bedload transport due to asymmetric and skewed waves. Coastal Engineering, 54(12): 914-929.

Hoefel, F. and Elgar, S., 2003. Wave-induced sediment transport and sandbar migration. Science, 299(5614): 1885-1887.

Lwin, K., Liu, H. and Sato, S., 2011. The role of steady streaming in sheetflow transport. Proceedings of the 6th International Conference on Asian and Pacific Coasts, Hongkong, China, p.^pp. 902-909. 
Madsen, O.S. and Grant, W.D., 1976. Sediment transport in the coastal environment. MIT Ralph M. Parsons Lab., Rep. 209, Cambridge, USA.

Mina, K.M. and Sato, S., 2004. A transport model for sheetflow based on two-phase flow. Coastal Engineering Journal (JSCE), 46(3): 329-367.

Nielsen, P., 1992. Coastal bottom boundary layers and sediment transport. Advanced series on ocean engineering, 4. World Scientific.

Nielsen, P., 2006. Sheet flow sediment transport under waves with acceleration skewness and boundary layer streaming. Coastal Engineering, 53(9): 749-758.

O'Donoghue, T. and Wright, S., 2004a. Concentrations in oscillatory sheet flow for well sorted and graded sands. Coastal Engineering, 50(3): 117-138.

O'Donoghue, T. and Wright, S., 2004b. Flow tunnel measurements of velocities and sand flux in oscillatory sheet flow for well-sorted and graded sands. Coastal Engineering, 51(11-12): 11631184.

Ribberink, J.S., 1998. Bed-load transport for steady flows and unsteady oscillatory flows. Coastal Engineering, 34(1-2): 59-82.

Ribberink, J.S. and Al-Salem, A.A., 1994. Sediment transport in oscillatory boundary layers in cases of rippled beds and sheet flow. Journal of Geophysical Research, 99(C6): 12,707-12,727

Ribberink, J.S. and Chen, Z., 1993. Sediment transport of fine sand under asymmetric oscillatory flow. Report H840, Part VII, Delft Hydraulics, The Netherlands.

Ruessink, B.G. et al., 2011. Observations of velocities, sand concentrations, and fluxes under velocityasymmetric oscillatory flows. Journal of Geophysical Research, 116(C3): C03004.

Ruessink, B.G., van den Berg, T.J.J. and van Rijn, L.C., 2009. Modeling sediment transport beneath skewed asymmetric waves above a plane bed. Journal of Geophysical Research, 114(C11): C11021.

Sato, S., Kabiling, M.B. and Suzuki, H., 1992. Prediction of near-bottom velocity history by a nonlinear dispersive wave model. Coastal Engineering Journal (JSCE), 35(1): 67-82.

Silva, P.A. et al., 2011. Sediment transport in nonlinear skewed oscillatory flows: Transkew experiments. Journal of Hydraulic Research, 49(sup1): 72-80.

Silva, P.A., Temperville, A. and Santos, F.S., 2006. Sediment transport under combined current and wave conditions: A semi-unsteady, practical model. Coastal Engineering, 53: 897-913.

Soulsby, R.L. and Whitehouse, R.J.S., 1997. Threshold of sediment motion in coastal environments. Proceedings of the 13th Australasian Coastal and Ocean Engineering Conference and the 6th Australasian Port and Harbour Conference, University of Canterbury, New Zealand, p.^pp. 149-154.

Van der A, D.A., 2010. Effects of acceleration skewness on oscillatory boundary layers and sheet flow sand transport. Phd Thesis, University of Aberdeen, UK, 205 pp.

Van der A, D.A., O'Donoghue, T. and Ribberink, J.S., 2010a. Measurements of sheet flow transport in acceleration-skewed oscillatory flow and comparison with practical formulations. Coastal Engineering, 57(3): 331-342.

Van der A, D.A., Van der Werf, J.J., Ribberink, J.S. and O'Donoghue, T., 2010b. New practical model for sand transport induced by non-breaking waves and currents, Proceedings 32th International Conference on Coastal Engineering, Shanghai, China.

Watanabe, A. and Sato, S., 2004. A sheet-flow transport rate formula for asymmetric, forward-leaning waves and currents. Proceedings 29th International Conference on Coastal Engineering, Lisbon, Portugal, p.`pp. 1703-1714. 